\title{
BIOSENSOR-LINKED IMMUNOSORBENT ASSAY FOR QUANTIFICATION OF METHIONINE OXIDATION IN TARGET PROTEINS
}

Hae Min Lee ${ }^{1}$, Dong Wook Choi ${ }^{2}$, Seahyun Kim ${ }^{1}$, Aro Lee ${ }^{1}$, Minseo Kim ${ }^{1}$, Yeon Jin Roh$^{1}$, Young Ho Jo ${ }^{1}$, Hwa Yeon Cho ${ }^{1}$, Ho-Jae Lee ${ }^{1}$, Seung-Rock Lee ${ }^{3}$, Lionel Tarrago ${ }^{4}$, Vadim N. Gladyshev ${ }^{5}$, Ji Hyung Kim ${ }^{1 *}$, Byung Cheon Lee ${ }^{1 *}$

1 Department of Biotechnology, College of Life Sciences and Biotechnology, Korea University, Seoul 02841, Republic of Korea

2 Department of Biochemistry, College of Natural Sciences, Chungnam National University, Daejeon 34134, Republic of Korea

${ }^{3}$ Department of Biochemistry, Research Center for Aging and Geriatrics, Chonnam National University Medical School, Gwangju 61186, Republic of Korea

${ }^{4}$ INRAE, Aix Marseille University, BBF, F13108, Marseille, France

5 Division of Genetics, Department of Medicine, Brigham and Women's Hospital, Harvard Medical School, Boston, MA 02215, USA

*Corresponding authors:

Ji Hyung Kim, Tel: +82-3290-3045, E-mail: jay_kim@korea.ac.kr

Byung Cheon Lee, Tel: +82-3290-3529, E-mail: cheonii@korea.ac.kr 


\section{TABLE OF CONTENTS}

Figure S1. Kinetic reactivity and $\mathrm{pH}$-dependence of tpMetROG

Table S1. Oligonucleotides used in this study.

Table S2. De novo synthesized DNA sequences. 
A

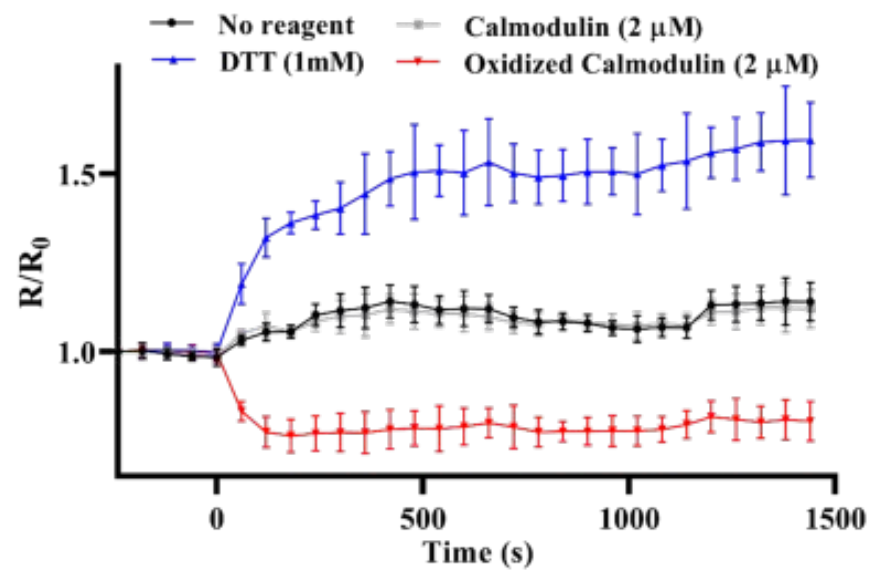

tpMetROG $(1 \mu \mathrm{M})+$ IDLO $(2 \mu \mathrm{M})$

tpMetROG $(1 \mu \mathrm{M})+$ oxidized IDLO $(2 \mu \mathrm{M})$

B $\quad \cdots$ tpMetROG ${ }^{\mathrm{C} 129 \mathrm{~S}}(1 \mu \mathrm{M})+\operatorname{IDLO}(2 \mu \mathrm{M})$

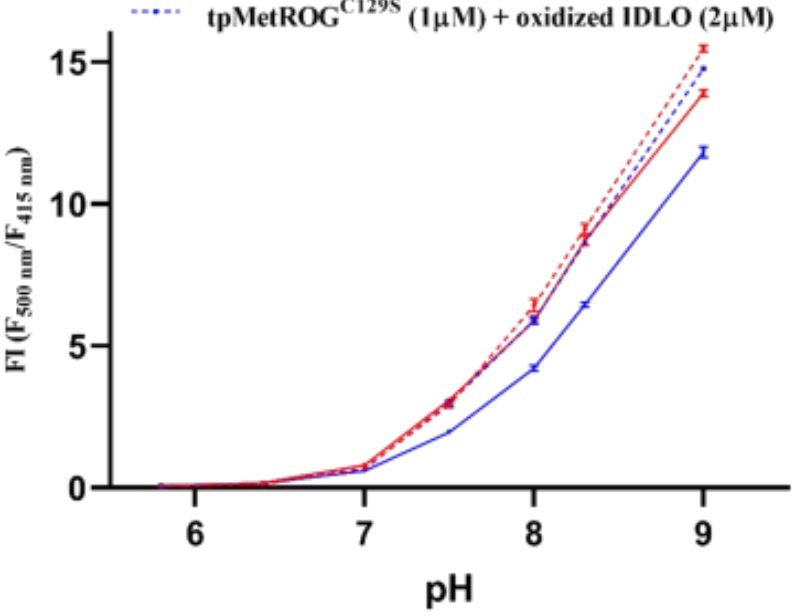

Figure S1. Kinetic reactivity and pH-dependence of tpMetROG (A) Kinetic of reactivity of tpMetROG with various proteins. tpMetROG $(1 \mu \mathrm{M})$ was incubated with calmodulin $(2 \mu \mathrm{M})$, partially oxidized calmodulin $(2 \mu \mathrm{M})$, and DTT $(1 \mathrm{mM}) . \mathrm{F}_{500 \mathrm{~nm}} / \mathrm{F}_{415 \mathrm{~nm}}$ ratios (R) were normalized to the value at $t=0\left(\mathrm{R}_{0}\right)$. (B) The fluorescence intensity (FI) ratio of tpMetROG and tpMetROG ${ }^{\mathrm{C} 129 \mathrm{~S}}$ under various $\mathrm{pH}$ conditions. FI $\left(\mathrm{F}_{500 \mathrm{~nm}} / \mathrm{F}_{415 \mathrm{~nm}}\right)$ was calculated for the excitation spectrum values with an emission wavelength of $535 \mathrm{~nm}$. tpMetROG or tpMetROG $^{\mathrm{C} 129 \mathrm{~S}}(1 \mu \mathrm{M})$ were incubated with $2 \mu \mathrm{M}$ IDLO or $2 \mu \mathrm{M}$ partially oxidized IDLO. Data are presented as means \pm SD and representative of 3 replicates. 
Table S1. Oligonucleotides used in this study.

\begin{tabular}{|c|c|c|c|}
\hline \# & Name & Sequence & Purpose \\
\hline 1 & MsrB For & $\begin{array}{l}\text { 5'- } \\
\text { AAGGATCCTGGAATAAGAGCAAGAAAATGAGTGA } \\
-3 \text { ' }\end{array}$ & PCR for MsrB \\
\hline 2 & MsrB Rev & $\begin{array}{l}\text { 5'-CATGATATAGACGTTATCCTTCTTGAGGTTTAA } \\
\text { AGACGCA-3' }\end{array}$ & PCR for MsrB \\
\hline 3 & cpYFP For & $\begin{array}{l}\text { 5'-ACCTCAAGAAGGATAACGTCTATATCATGGCCG } \\
\text { ACAAG-3' }\end{array}$ & PCR for cpYFP \\
\hline 4 & cpYFP Rev & $\begin{array}{l}\text { 5'-GTATGAGGACATGTTGTACTCCAGCTTGTGCCC- } \\
3 \text {, }\end{array}$ & PCR for cpYFP \\
\hline 5 & Trx3 For & $\begin{array}{l}\text { 5'-GCTGGAGTACAACATGTCCTCATACACCAGTAT } \\
\text { TACTAAATTGAC-3' }\end{array}$ & PCR for Trx3 \\
\hline 6 & Trx3 Rev & $\begin{array}{l}\text { 5'-GCCTCTGCCAGTAGATCTTTGATTCCCTTCTCT } \\
\text { AAAGCAG-3' }\end{array}$ & PCR for Trx3 \\
\hline 7 & Flexible linker For & 5'-CAAAGATCTACTGGCAGAGGCAGCC-3' & PCR for flexible linker \\
\hline 8 & Flexible linker Rev & 5'-ACCATGGCCAGCCGCCGCTTTCG-3' & PCR for flexible linker \\
\hline 9 & Protein G For & 5'-GGCGGCTGGCCATGGTTCTTCTATGACTAC-3' & PCR for protein $\mathrm{G}$ \\
\hline $\begin{array}{l}1 \\
0\end{array}$ & Protein G Rev & $\begin{array}{l}\text { 5'-AACTCGAGTTCAGTAACTGTAAAGGTCTTAGTC } \\
\text { GC-3' }\end{array}$ & PCR for protein $G$ \\
\hline $\begin{array}{l}1 \\
1\end{array}$ & $\begin{array}{l}\text { MsrB/cpYFP/Trx3/Flexible } \\
\text { linker For }\end{array}$ & $\begin{array}{l}\text { 5'-AAGGATCCAAGAGCAAGAAAATGAGTGACG } \\
\text { AAT-3' }\end{array}$ & $\begin{array}{l}\text { Create tpMetROG }{ }^{\Delta \text { protein }} \mathrm{G} \\
\text { sensor in pET } 21 \mathrm{a}\end{array}$ \\
\hline $\begin{array}{l}1 \\
2\end{array}$ & $\begin{array}{l}\text { MsrB/cpYFP/Trx3/Flexible } \\
\text { linker_Rev }\end{array}$ & 5'-AACTCGAGAGCCGCCGCTTTCGCG-3' & $\begin{array}{l}\text { Create tpMetROG }{ }^{\Delta \text { protein }} \mathrm{G} \\
\text { sensor in pET 21a }\end{array}$ \\
\hline $\begin{array}{l}1 \\
3\end{array}$ & tpMetROG_MsrB_C129S_For & 5'-GACACCAGACACAGTGTGAACAGTGC-3' & $\begin{array}{l}\text { Cys } 129 \text { to Ser site directed } \\
\text { mutagenesis (MsrB moiety) }\end{array}$ \\
\hline $\begin{array}{l}1 \\
4\end{array}$ & tpMetROG_MsrB_C129S_Rev & 5'-CGCACTGTTCACACTGTGTCTGGT-3' & $\begin{array}{l}\text { Cys } 129 \text { to Ser site directed } \\
\text { mutagenesis (MsrB moiety) }\end{array}$ \\
\hline $\begin{array}{l}1 \\
5\end{array}$ & tpMetROG_Trx3_C422S_For & 5'-CTTGGTGTGGCCCCTCTAAGATGATGC-3' & $\begin{array}{l}\text { Cys } 422 \text { to Ser site directed } \\
\text { mutagenesis (Trx3 moiety) }\end{array}$ \\
\hline $\begin{array}{l}1 \\
6\end{array}$ & tpMetROG_Trx3_C422S_Rev & 5'-GCATCATCTTAGAGGGGCCACACCAAG-3' & $\begin{array}{l}\text { Cys } 422 \text { to Ser site directed } \\
\text { mutagenesis (Trx3 moiety) }\end{array}$ \\
\hline
\end{tabular}


Table S2. De novo synthesized DNA sequences

\begin{tabular}{|l|l|l|}
\hline$\#$ & Name & Sequence \\
\hline 1 & Flexible linker & $\begin{array}{l}\text { 5'- } \\
\text { CTGGCAGAGGCAGCCGCCAAGGAAGCGGCTGCTAAAGAAGCAGCAGCTAAAGAAGCGGCC } \\
\text { GCGAAAGCGGCGGCT-3' }\end{array}$ \\
\hline 2 & & 5 '- \\
& Protein G & GGCCATGGTTCTTCTATGACTACTTACAAATTAATCCTTAATGGTAAAACATTGAAAGGCGA \\
& & AACAACTACTGAAGCTGTTGATGCTGCTACTGCAGAAAAAGTCTCAAACAATACGCTAACG \\
& & ACAACGGTGTTGACGGTGAATGGACTTACGACGATGCGACTAAGACCTTTACAGTTACTGAA \\
& & \\
\hline
\end{tabular}

